\title{
Xanthogranulomatous prostatitis with prostato-rectal fistula: a case report and review of the literature
}

This article was published in the following Dove Press journal:

Research and Reports in Urology

16 September 2016

Number of times this article has been viewed

\section{Liyong Xing \\ Zhifei Liu \\ Gang Deng \\ Huan Wang \\ Yanfeng Zhu \\ Peng Shi \\ Bingyue Huo \\ Yindong Li}

Department of Urology, Tangshan People's Hospital, Tangshan, People's Republic of China
Correspondence: Zhifei Liu

Department of Urology, Tangshan People's Hospital, 65 Shengli Road, Tangshan 063000, People's Republic of China

Email liuzhifeil 107@I63.com
Purpose: Xanthogranulomatous prostatitis (XP) is a rare form of nonspecific granulomatous prostatitis that can clinically mimic high-grade prostatic carcinoma. It is difficult to diagnose it definitely in clinical settings.

Methods: We report a case of XP with prostate-rectal fistula and review the relevant literatures. Result: A 75-year-old man presented with rectal bleeding when he urinated. A locally advanced carcinoma of prostate was suspected initially following the physical, imaging, and hematologic examinations. Subsequently on histopathological and immunohistochemical staining after needle biopsy of the prostate, a diagnosis of XP was made definitely. The patient was catheterized temporarily and treated with tamsulosin and estrogen. The patient underwent uneventful recovery after this conservative therapy.

Conclusion: Histologic and immunohistochemical analyses are valuable in differentially diagnosing XP from high-grade prostate carcinoma. Treatment strategy of XP in principle is recommended to be the conservative method. Long-term follow-up earns are highly regarded considering the possibility of coexisting prostate cancer.

Keywords: xanthogranulomatous prostatitis, prostate-rectal fistula

\section{Introduction}

Xanthogranulomatous prostatitis (XP) is an unusual benign inflammatory lesion of prostate that can mimic prostatic carcinoma in clinical presentation and imaging characteristics, pathologically characterized by the presence of large lipid-laden macrophages. ${ }^{1}$ Prostate-rectal fistula is a rare condition. The causative factors of the fistulae encompass prostate abscess, prostate carcinoma, and brachytherapy for prostate cancer. To the best of our knowledge, XP with prostate-rectal fistula has not been reported in the world. Herein, we report a patient with prostate-rectal fistula caused by XP.

\section{Case presentation}

A 75-year-old man was admitted to Department of Urology, Tangshan People's Hospital with a complaint of rectal bleeding when he urinated. He had a history of hesitancy, weak flow, intermittency, and increased urinary frequency for 3 months. His International Prostate Symptom Score was 25 . He had no significant past medical history, and his general physical examination was normal. He had not experienced any fever or any significant loss of weight. Digital rectal examination (DRE) revealed a prostate with hard consistency and indurated nodular (which was suspicious of malignancy) but without tenderness. The glove was covered with blood when the index finger was withdrawn 
gently. The serum prostate-specific antigen (PSA) level was $172.5 \mathrm{ng} / \mathrm{mL}$. Transrectal ultrasonography (TRUS) showed an enlarged prostate gland with thickened bladder wall. The prostate was $4.3 \times 3.8 \times 5.0 \mathrm{~cm}^{3}$ in size with especially an enlarged central gland and inhomogeneous echogenicity and calcification in the peripheral zone. Postmicturition residual urine was $200 \mathrm{~mL}$. Pelvic magnetic resonance imaging (MRI) revealed an enlarged irregular prostate gland; the central zones of the gland were markedly enlarged and nonisosignal, and the morphology of the peripheral gland was of low-signal intensity. A part of the prostate gland protruded to the bladder, and a fistula existed between the prostate and rectum (Figure 1).

A provisional diagnosis of locally advanced prostatic carcinoma was made. The patient underwent a TRUS-guided biopsy. Histopathology of the specimen revealed large numbers of "foamy macrophages" involving in the lesion, infiltration of multinucleated giant cell, leukomonocyte, and plasmocyte. Moreover, fibroplasias can also be seen (Figure 2). The immu-

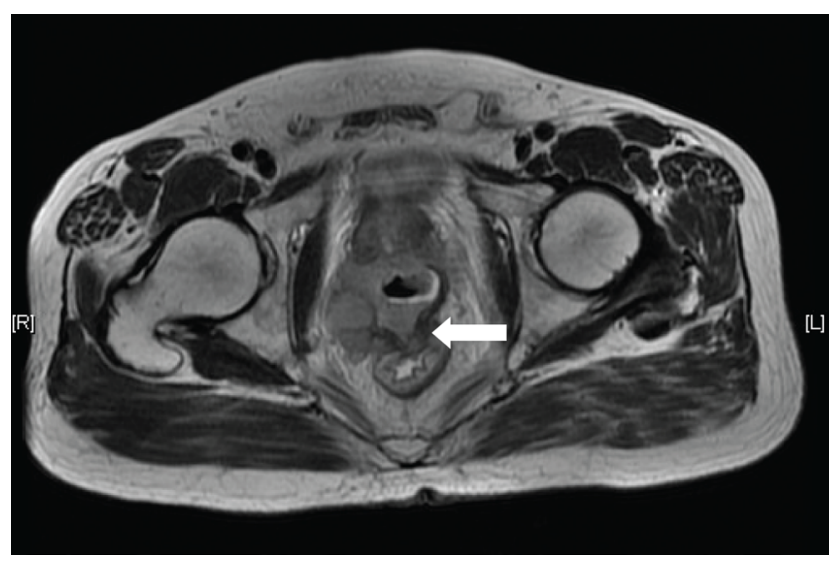

Figure I MRI (T2 weighted) showing an enlarged irregular prostate gland and prostate-rectal fistula (white arrow).

Abbreviation: MRI, magnetic resonance imaging.

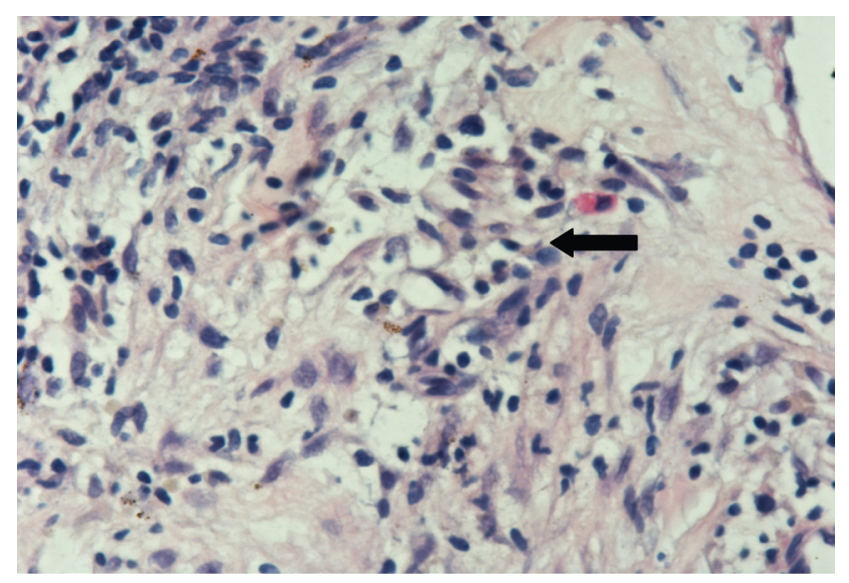

Figure 2 Photomicrograph showing large numbers of foamy macrophages (black arrow) involved in the lesion (hematoxylin and eosin, $\times 400$ ).

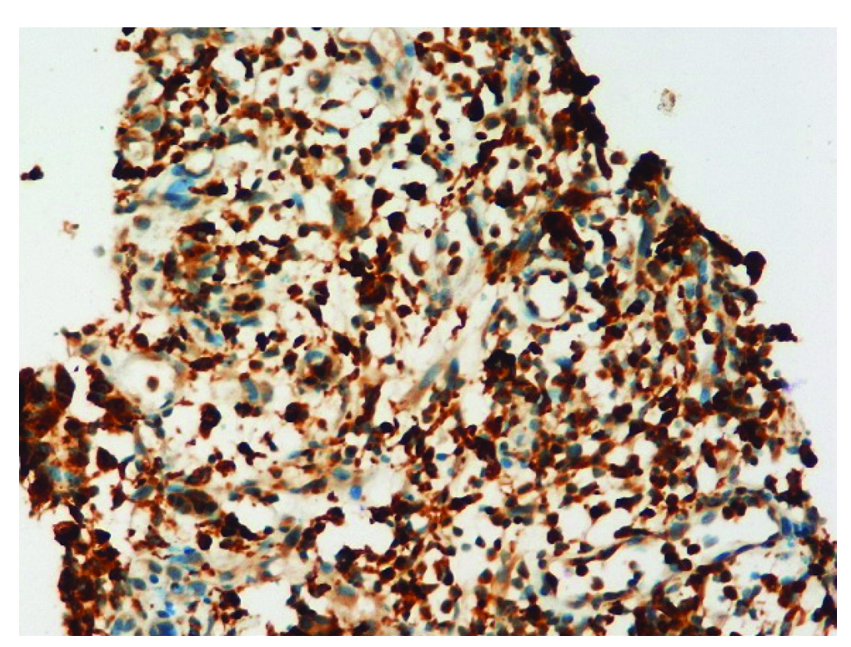

Figure 3 The histiocytes and giant cells show intense reactivity for CD68 (hematoxylin and eosin, $\times 200$ ).

nohistochemical stains showed CD68 (+) (Figure 3) and PSA $(-)$. Benign prostatic glands were identified, and no evidence of malignancy was noted. It was diagnosed as XP definitely. Tamsulosin and estrogen were given, and temporary catheterization was performed. After 4 months follow-up, the patient remained symptom free and his serum PSA began to decrease. After 17 months, his PSA had decreased to $<4 \mathrm{ng} / \mathrm{mL}$.

This study has been approved by the Ethics Committee of Tangshan People's Hospital. The patient who was enrolled in this study has signed the written informed consent form.

\section{Discussion}

XP was first described by Tanner and McDonald in 1943, ${ }^{2}$ and the first classification of XP was mentioned by Symmers in $1950 .{ }^{3} \mathrm{XP}$ is a rare form of nonspecific granulomatous prostatitis that can clinically mimic high-grade prostatic carcinoma. ${ }^{4}$ Such lesions have been described in many anatomic sites, such as the mandible, retroperitoneum, third ventricle, choroid plexus, orbit, kidney, vagina, gallbladder, lung, stomach, pericardium, and ovary. ${ }^{5}$

Xanthogranulomatous inflammation is a rare clinicalpathological condition involving many systems. It is well known in the kidney and gallbladder, but prostate involvement with this inflammation was rarely reported. ${ }^{6}$ The etiology and pathogenesis of XP remain unknown. It may be associated with hyperlipidemia, ${ }^{7}$ but other investigators considered that it may be an autoimmune disease with a HLA-DR15-linked T-cell response against proteins in prostatic secretions, principally PSA. ${ }^{8}$ Bostwick and Chang ${ }^{9}$ speculated that XP probably results from blockage of prostate ducts and stasis of secretions. The cellular debris, bacterial toxins, prostatic secretions, sperm, and semen escape into the stroma through the destroyed epithelium, eliciting a localized inflammatory response. 
XP occurs in elderly men and is usually found in patients undergoing transurethral resection or needle biopsy. Clinically, the most common symptoms (lower urinary tract symptoms [LUTS]) include hesitancy, weak flow, intermittency, and urinary frequency, similar to benign prostate hyperplasia, sometimes with the symptoms of severe urinary tract infection. In addition, presentation of similar-to-acute prostatic abscess has also been reported..$^{10}$ DRE, TRUS, and MRI findings play an important role in the differential diagnosis of prostatic lesions. In our case, DRE revealed hard and irregular prostate. Echography and MRI findings are comparable to those observed in prostate cancer. It appears that there is no pattern of clinical, biochemical, ultrasound or MRI findings that allows a specific diagnosis of granulomatous prostatitis to be made or differentiation from prostatic carcinoma. ${ }^{11}$ In addition, granulomatous prostatitis may cause a transient increase in the serum PSA level, which decreases with a resolution of the inflammation. ${ }^{12}$ In the present case, the serum PSA level was markedly elevated at $172.5 \mathrm{ng} / \mathrm{mL}$ and resolved to the normal level at his last clinical follow-up.

The diagnosis of XP is based on histological examination of prostate. It is characterized by an occurrence of nonspecific granulation, mainly consisting of foamy macrophages that are macrophages containing a lot of fat drops in the infiltrated inflammatory cell and may be associated with other chronic inflammatory cell infiltration, such as lymphocytes and plasma cells. Inflammatory cells and hyperplasia of fibrous tissue together form tumor sample nodules; these nodules' sample structure often exists in the expansion of the gland tube or gland bubble around, such like high-grade prostatic carcinoma and sometimes it is difficult to distinct. ${ }^{7}$ In such cases, immunohistochemical stains, such as PSA and histiocyte marker, can help addressing an accurate diagnosis. ${ }^{13,14}$ In the present case, the histiocytes and giant cells showed intense reactivity for CD68 but negative for PSA.

So far, the treatment of XP patients remains a therapeutic problem unsolved. Conservative treatment should be considered in principle. Slow regression of clinical symptoms and findings on palpation has been reported. ${ }^{15}$ In conservative treatment, apart from antibacterial drugs, alpha blockers and corticosteroids may be helpful. If the LUTS are significant, an operation of TURP or open prostatectomy is appropriate and safe. However, post-TURP, a rectovesical fistula had been reported in one case of XP. ${ }^{16}$ It has been reported that $19 \%$ of patients developed prostate carcinoma, with an average presentation time of 5.5 years after nonspecific granulomatous prostatitis diagnosis ${ }^{17}$; in this regard, a close follow-up is recommended, especially in patients with persisting elevated serum PSA values. If elevated PSA levels persist, it should raise the suspicion of coexisting carcinoma.

Prostate-rectal fistula can be caused by prostatic abscess spontaneously perforating into rectum, and it may be a complication of brachytherapy for prostate carcinoma. None of the studies documented inflammatory or benign disease of the prostate as a cause of fistula development. ${ }^{18}$ In our case, we speculated that the fistula may be a consequence of chronic inflammation stimulation caused by XP or a coexisting prostate abscess, but there were no exact evidences to confirm.

\section{Conclusion}

$\mathrm{XP}$ is uncommon, and $\mathrm{XP}$ with prostate-rectal fistula is even rarer. Histologic and immunohistochemical analyses are valuable for a differential diagnosis from high-grade prostatic carcinoma. Treatment of XP should be conservative in principle; only the cases with heavy LUTS will eventually need an operation. Close follow-up is crucial to detect the coexisted carcinoma.

\section{Disclosure}

The authors report no conflicts of interest in this work.

\section{References}

1. Kuo TL, Cheng C. Xanthogranulomatous inflammation of urachus mimicking urachal carcinoma. Urology. 2009;73(2):443.e13-443.e14.

2. Tanner F, McDonald J. Granulomatous prostatitis: a histologic study of a group of granulomatous lesions collected from prostate glands. Arch Pathol. 1943;36:358-370.

3. Symmers WSC. Non-specific granulomatous prostatitis. Br J Urol. 1950;22(1):6-20.

4. Srigley JR. Benign mimickers of prostatic adenocarcinoma. Mod Pathol. 2004;17(3):328-348.

5. Walther M, Glenn JF, Vellios F. Xanthogranulomatous cystitis. J Urol. 1985;134:745-746.

6. Rafique M, Yaqoob N. Xanthogranulomatous prostatitis: a mimic of carcinoma of prostate. World J Surg Oncol. 2006;4:30.

7. Sebo TJ, Bostwick DG, Farrow GM, Eble JN. Prostatic xanthoma: a mimic of prostatic adenocarcinoma. Hum Pathol. 1994;25(4): 386-389.

8. Alexander RB, Mann DL, Borkowski AA, et al. Granulomatous prostatitis linked to HLA-DRB1*1501. J Urol. 2004;171(6 pt 1):2326-2329.

9. Bostwick DG, Chang L. Overdiagnosis of prostatic adenocarcinoma. Semin Urol Oncol. 1999;17(4):199-205.

10. Valsangkar RS, Singh DP, Gaur DD. Xanthogranulomatous prostatitis: rare presentation of rare disease. Indian J Urol. 2012;28(2): 204-205.

11. Naik KS, Carey BM. The transrectal ultrasound and MRI appearances of granulomatous prostatitis and its differentiation from carcinoma. Clin Radiol. 1999;54(3):173-175.

12. Speights VO Jr, Brawn PN. Serum prostate specific antigen levels in non-specific granulomatous prostatitis. Br J Urol. 1996;77(3): $408-410$. 
13. Presti B, Weidner N. Granulomatous prostatitis and poorly differentiated prostate carcinoma. Their distinction with the use of immunohistochemical methods. Am J Clin Pathol. 1991;95(3):330-334.

14. Val-Bernal JF, Zaldumbide L, Garijo MF, Gonzalez-Vela MC. Nonspecific (idiopathic) granulomatous prostatitis associated with low-grade prostatic adenocarcinoma. Ann Diagn Pathol. 2004;8(4):242-246.

15. Matsumoto T, Sakamoto N, Kimiya K, Kumazawa J, Miyazaki N, Hasegawa Y. Nonspecific granulomatous prostatitis. Urology. 1992;39(5): $420-423$.
16. Zaber K, MBcHB C, Al-Bareeq R; MRCSI. Xanthogranulomatous prostatitis causing entero-vesical fistula. Bahrain Med Bull. 2004;26(4).

17. Osca Garcia JM, Alfaro Ferreres L, Vera Donoso CD, Ruiz Cerda JL, Martinez Jabaloyas JM, Jimenez Cruz JF. [Non-specific granulomatous prostatitis. Relationship and differential diagnosis with prostatic cancer]. Actas Urol Esp. 1994;18(4):287-290.

18. Sadamoto Y, Araki Y, Harada N, Hamada S, Chijiiwa Y, Nawata H. A case of rectoprostatic fistula due to prostatic abscess visualized by barium enema. Br J Radiol. 1999;72(862):1016-1017.

\section{Publish your work in this journal}

Research and Reports in Urology is an international, peer-reviewed, open access journal publishing original research, reports, editorials, reviews and commentaries on all aspects of adult and pediatric urology in the clinic and laboratory including the following topics: Pathology, pathophysiology of urological disease; Investigation and treatment of urological disease; Pharmacology of drugs used for the treatment of urological disease. The manuscript management system is completely online and includes a very quick and fair peer-review system, which is all easy to use. Visit http://www.dovepress.com/testimonials.php to read real quotes from published authors.

Submit your manuscript here: https://www.dovepress.com/research-and-reports-in-urology-journal 